\title{
Actividades pesqueras dependientes de la ictiofauna en el Pacífico Norte de Costa Rica
}

\author{
Fresia Villalobos-Rojas ${ }^{1}$, Juliana Herrera-Correal ${ }^{2}$, Carlos A. Garita-Alvarado ${ }^{2}$, Tayler Clarke ${ }^{1}$ \& \\ Andrés Beita-Jiménez ${ }^{1,2}$ \\ 1. Unidad de Investigación Pesquera y Acuicultura (UNIP), Centro de Investigación en Ciencias del Mar y Limnología, \\ Universidad de Costa Rica, 11501-2060 San José, Costa Rica; v.fresia@gmail.com, taylermc@gmail.com, \\ abeitaj@gmail.com \\ 2. Escuela de Biología, Universidad de Costa Rica; julianaherrera17@hotmail.com, cagaritab@gmail.com
}

Recibido 13-V-2014. Corregido 23-VII-2014. Aceptado 27-IX-2014.

\begin{abstract}
Economic activities that depend on ichthyofauna in the North Pacific of Costa Rica. The North Pacific of Costa Rica is characterized by a large diversity of fish species. This diversity sustains two of the main economic activities developed there: fishing and tourism. We synthesized information from: semistructured interviews with local stakeholders, biodiversity database from the Museo de Zoología, Universidad de Costa Rica, landings database from Costa Rican government (INCOPESCA) and the literature. A total of 424 fish species are reported from the area and the main target species for each fishery are: mahi-mahi, silky shark, hammerhead shark, tuna, sailfish, swordfish for longline fisheries; snappers, croakers, snook and groupers for artisanal fisheries; invertebrates and ornamental fish in dive-fisheries; shrimp in trawl fisheries; and wahoo, yellow-fin tuna, rooster fish, mahi-mahi, swordfish, sailfish, marlin in tourism fisheries. INCOPESCA does not take into account fishing effort but most species landings are decreasing, especially mahi-mahi, groupers and snappers. Conflicts between fisheries and tourism are arising due to competition for resources and overexploitation. The main conflicts found were: (1) between sport and longline fisheries, (2) between recreational diving and dive-fisheries, (3) between the artisanal and shrimp trawling fisheries, and (4) among artisanal fishermen from different zones of the Pacific. These conflicts demonstrate the urgency of developing and effectively implementing management strategies that will guarantee the sustainability of fish resources in the area. Future studies should focus on generating information that will guide and support these management efforts. Rev. Biol. Trop. 62 (Suppl. 4): 119-138. Epub 2014 Diciembre 01.
\end{abstract}

Key words: fish, artisanal; longline; tourism; scuba diving; fisheries.

El Pacífico Norte de Costa Rica (desde Cabo Blanco hasta Nicaragua) presenta una gran variedad de ambientes marino-costeros: arrecifes coralinos, manglares, pastos marinos, fondos lodosos, zonas rocosas, islas costeras, playas, acantilados, áreas de surgencia, entre otros (SINAC, 2009b). Estos ambientes sirven de hábitat para una gran diversidad de peces (Bussing \& López, 2009, SINAC, 2009a, Cortés $\&$ Wehrtmann, 2009). A pesar de que no existen estimaciones específicas de la diversidad de peces, se sugiere que ésta podría albergar una gran cantidad de especies. Por ejemplo, solamente para Bahía Culebra se han reportado 82 especies de peces (Cortés, 2012a). Hay pocos estudios publicados sobre aspectos biológicos específicamente del Pacífico Norte de Costa Rica, con la excepción de Bahía Culebra (en el Golfo de Papagayo) (Cortés, 2012a, b; Cortés, Vargas-Castillo, Nivia-Ruíz, 2012). Las pocas publicaciones sobre peces de la zona se enfocan en la ecología de peces arrecifales (Jiménez, 1997; Dominici-Arosemena, Brugnoli-Olivera, Cortés-Núñez, Molina-Ureña \& Quesada-Alpízar, 2005; Espinoza \& Salas, 2005; Bussing \& López, 2009; Cortés, 2012b; Jiménez, 2013).

En la zona marino-costera del Pacífico Norte se realiza una gran variedad de 
actividades económicas dependientes de la ictiofauna, que pueden clasificarse en extractivas y no extractivas. Las principales actividades extractivas son la pesca de palangre, artesanal, de buceo con compresor, arrastre, turística y extracción de peces ornamentales (EspinozaMendiola \& Nielsen-Muñoz, 2006). Mientras que las actividades no-extractivas más frecuentes están relacionadas con el turismo (buceo recreativo, esnórquel, entre otros). Muchas de estas actividades compiten entre sí por el recurso, causando conflictos entre sectores.

El Pacífico Norte es una de las zonas con mayor crecimiento en el sector del turismo y la pesca en Costa Rica. En los últimos 30 años ha aumentado el impacto del desarrollo turístico y pesquero sobre los ambientes marino-costeros y las poblaciones de peces que la habitan (Nanne, 2003). Sin embargo, se desconoce el estado de las pesquerías y de los recursos marinos que son aprovechados en esta zona. El presente trabajo caracteriza las actividades pesqueras dependientes de la ictiofauna del Pacífico Norte costarricense identifica los principales conflictos presentes entre las diferentes actividades.

\section{MATERIALES Y MÉTODOS}

El Pacífico Norte de Costa Rica comprende la zona desde la frontera con Nicaragua hasta Cabo Blanco. Su territorio está dividido administrativamente en dos provincias: Guanacaste y Puntarenas. A su vez las Áreas Silvestres Protegidas (ASP) del Pacífico Norte están gestionadas por dos áreas de conservación: Área de Conservación Guanacaste (ACG) y Área de Conservación Tempisque (ACT) (Nielsen-Muñoz \& Quesada-Alpízar, 2006). Hasta la fecha, existen seis ASP que poseen al menos un componente marino-costero: Parque Nacional Santa Rosa, Refugio Nacional de Vida Silvestre Camaronal, Refugio Nacional de Vida Silvestre Ostional, Refugio Nacional de Vida Silvestre Caletas Arío, Reserva Nacional Absoluta Cabo Blanco y Parque Nacional Marino Las Baulas (exclusivamente marino-costero) (Cortés, 1996-1997; SINAC, 2009; SINAC,
2010). Además existe el Área Marina de Pesca Responsable (AMPR) San Juanillo, como parte de la Red Nacional de AMPR (Solano, 2014). Según PROAMBIENTE (1999), existen 15 comunidades de pescadores en el Pacífico Norte: Cuajiniquil, Playas del Coco, Brasilito, Tamarindo, Lagarto, San Juanillo, Playa Las Peladas, Playa Guiones, Playa Garza, Sámara, Puerto Carrillo, Puerto Coyote, Bejuco, Malpaís y Cabuya (Fig. 1).

La información utilizada para caracterizar la situación de los recursos y actividades pesqueras asociadas a los peces del Pacífico Norte de Costa Rica se obtuvo de cuatro fuentes de información: (1) base de datos del departamento de estadísticas pesqueras del Instituto Nacional de Pesca y Acuicultura (INCOPESCA), (2) base de datos de la colección de peces del Museo de Zoología de la Universidad de Costa Rica, (3) dos giras de campo a localidades de la zona y (4) revisión bibliográfica.

La información de las bases de datos de INCOPESCA fue obtenida a través del sitio web oficial de la institución (http://www.incopesca.go.cr/publicaciones/estadisticas.html), en el cual hay datos de los desembarques por clase comercial desde el año 1990 hasta el 2009. Para la identificación de las clases comerciales presentes en la base de datos se utilizó el Manual de especies comerciales elaborado por INCOPESCA y Ross-Salazar, Posada, Melo, Suárez, \& Ventura-Pozuelo (2014). Las bases de datos fueron analizadas con el fin de obtener información general sobre las descargas de los recursos. Debido a que no se especifica el tipo de flota del cual provienen las descargas, el análisis de la información por flota pesquera no fue posible.

A partir de la base de datos del Museo de Zoología se obtuvo una lista de especies que brinda una aproxima la diversidad de especies en la zona. Se dividió el Pacífico Norte en cinco zonas (1. desde Puerto Soley hasta Santa Elena, 2. desde Santa Elena hasta el Parque Nacional Marino las Baulas (PNMB), 3. desde el PNMB hasta Ostional, 4. desde Ostional hasta Puerto Carrillo y 5. Puerto Carrillo hasta Montezuma) 

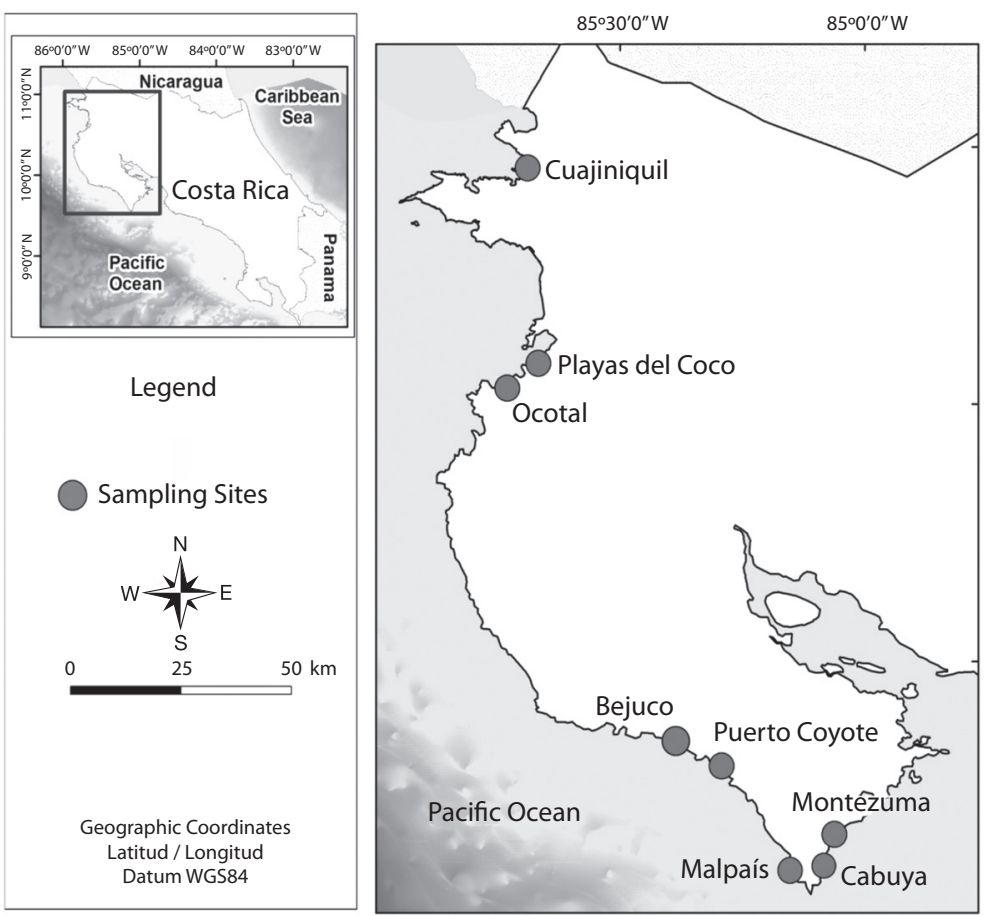

Fig. 1. Localidades visitadas con el fin de hacer las entrevistas y consultas, Pacífico Norte de Costa Rica.

Fig. 1. Communities visited in order to make interviews and consultations, North Pacific Costa Rica.

con el fin de identificar en que sitios hay más reportes y registros de especies de peces.

Se realizaron dos giras de campo al Pacífico Norte (marzo y julio del 2012), donde se visitaron ocho localidades: Cuajiniquil, Playas del Coco, Ocotal, Puerto Coyote, Bejuco, Malpaís, Cabuya y Montezuma (Fig. 1). Durante estas giras se realizaron entrevistas semi-estructuradas (de tipo conversación informal), a los pescadores artesanales, centros de acopio, recibidores de pescado, centros de pesca turística, personas involucradas en conservación, entidades gubernamentales (Instituto Costarricense de Pesca y Acuicultura, INCOPESCA y el Ministerio del Ambiente, Energía y Telecomunicaciones MINAET) (Cuadro 1). No se pudo homogenizar la información obtenida para todos los sitios visitados, debido a que en cada localidad no están presentes todas las fuentes de información.

Durante las conversaciones con pescadores artesanales se obtuvo información sobre organización pesquera, principales recursos pesqueros, características del arte de pesca, tiempo dedicado a la actividad, épocas de pesca, logística de comercialización del recurso, percepción de las ASP, problemáticas actuales y la visión en el futuro de su actividad productiva. En los centros de acopio y recibidores de pescado, se obtuvo información acerca de las principales especies recibidas, tipo de pesca de la que provienen las descargas, tendencias generales de los recursos, percepción de las ASP, problemáticas actuales y visión futura de su actividad productiva. El sector de la conservación de recursos naturales brindó información acerca de la relación con actividades económicas extractivas y no extractivas, las tendencias generales de los recursos, problemáticas y dificultades actuales y visión futura de los recursos. En las entidades gubernamentales se obtuvo información acerca de generalidades de flota pesquera, principales recursos y zonas pesqueras, tendencias generales de los recursos, 


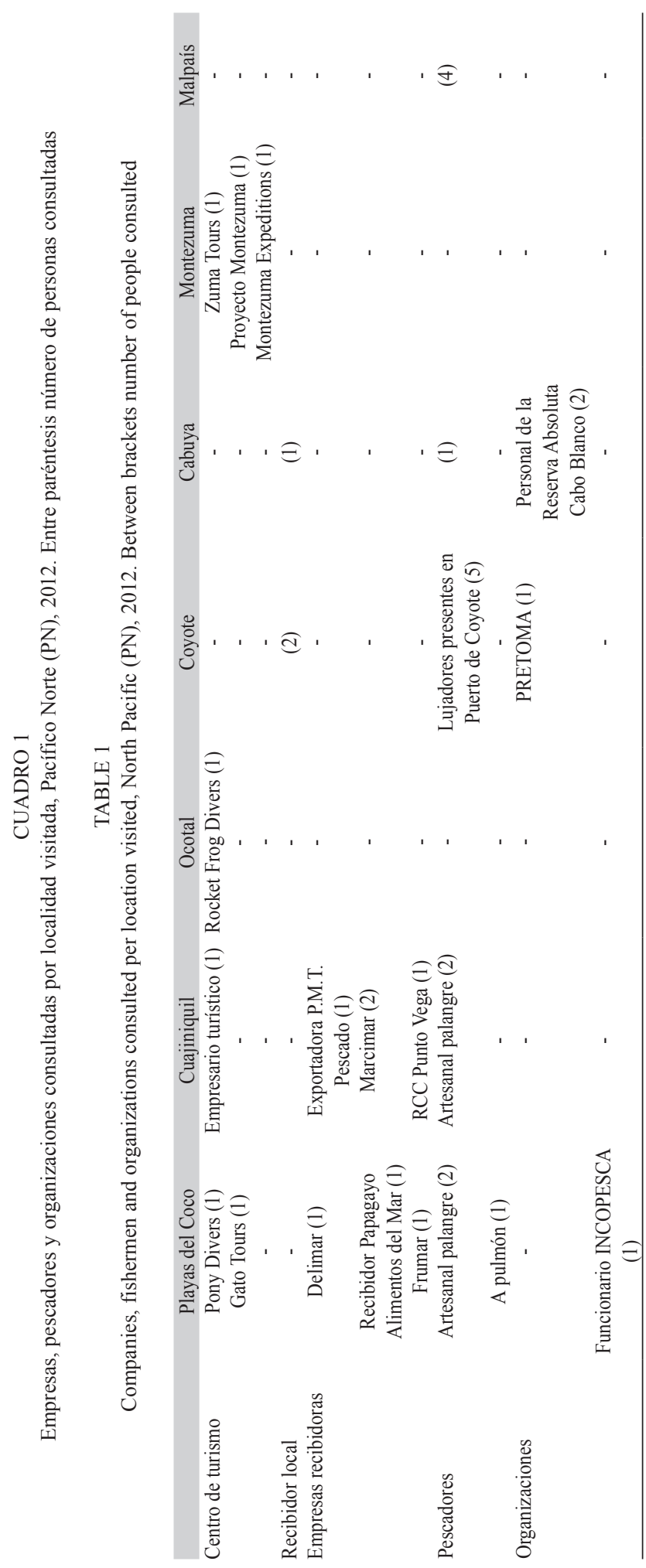


problemáticas y dificultades actuales y visión futura de los recursos. La revisión bibliográfica incluyó trabajos realizados (tesis, reportes, artículos científicos, documentos legales, entre otros) en temas relacionados con las distintas pesquerías de la zona.

Con el fin de facilitar el análisis de información, las actividades económicas extractivas realizadas en el Pacífico Norte de Costa Rica se categorizaron de la siguiente manera: pesca de palangre, pesca artesanal, pesca de peces de arrecife, pesca de arrastre, pesca turística. Al asociarse con los tipos de pesca encontrados en la Ley de Pesca y Acuicultura (Ley 8436, 2005) las categorías se definen de la siguiente manera:

Pesca de palangre. Incluida dentro de los tipos de pesca comercial de mediana escala y comercial avanzada. Se define como “....arte de pesca selectivo que utiliza una línea madre en la cual se colocan reinales con anzuelos debidamente encarnados, para capturar especies pelágicas y demersales."

Pesca artesanal. Incluida dentro de la pesca comercial de pequeña escala. Está definida como "actividad de pesca realizada en forma artesanal por personas físicas, con uso de embarcación, en las aguas continentales o en la zona costera y con una autonomía para faenar, hasta un máximo de cinco millas náuticas del litoral que se realiza con propósitos comerciales".

Pesca mediante buceo. No está definida en ninguna categoría de pesca de la Ley de Pesca. Para fines de este trabajo nos referimos a este tipo pesca a las actividades de extracción directa mediante el uso de buceo autónomo, con compresor o esnórquel.

Pesca de arrastre. Incluida dentro de la pesca comercial semi-industrial. En la Sentencia $\mathrm{N}^{\circ} 2013-10540$ (2013) se describe como el arte que "consiste en arrastrar las redes sobre el fondo, mientras que grandes cadenas son utilizadas como lastre y mantienen la red pegada al fondo".
Pesca turística. No está incluida como parte de la pesca comercial. Se define dentro de la ley como "la actividad pesquera que realizan personas físicas, nacionales o extranjeras, con el fin de capturar, con un aparejo de pesca personal apropiado para el efecto, recursos acuáticos pesqueros en aguas continentales, jurisdiccionales o en la zona económica exclusiva, con fines comerciales y propósitos exclusivamente turísticos, llevados a cabo en forma permanente".

\section{RESULTADOS}

Con la información generada a partir de las bases de datos del Museo de Zoología obtuvimos un total de 424 especies de peces, pertenecientes a 97 familias. La mayoría de las especies se han colectado en los alrededores de la Zona 2. (desde Santa Elena hasta el PNMB), con un total de 346 especies y 1020 registros (Fig. 2). Mientras que la Zona 5. (entre Puerto Garza y Montezuma) obtuvo la menor cantidad de especies, con un total de 24 especies de 34 registros (Fig. 2). Otros autores presentan listas de especies principalmente en zonas arrecifales (ver Dominici-Arosemena et al. 2005, Espinoza y Salas 2005).

Pesca de palangre. Este grupo incluye la pesca con palangre de deriva y en el país solo se permiten embarcaciones con bandera nacional (Ross-Salazar, 2014) El arte de pesca utilizado por esta flota está compuesto por una línea madre de 20 a $40 \mathrm{~km}$ de largo, con una cantidad desde 500 hasta 1000 anzuelos circulares (\#14 y \#15) colocados cada $25 \mathrm{~m}$. Las carnadas utilizadas por esta flota son sardinas (Opisthonema spp.), calamares, tiburones o peces de bajo valor capturados por la misma embarcación. Los sitios de pesca se encuentran tanto dentro de la Zona Económica Exclusiva de Costa Rica (ZEE), como en aguas internacionales, aproximadamente entre los 65 a más de $320 \mathrm{~km}$ de la costa (Whoriskey, Arauz \& Baum, 2011, Dapp, Arauz, Spotila \& O'Connor, 2013). Esta actividad pesquera permite capturar especies pelágicas que pueden clasificarse en dos tipos: 


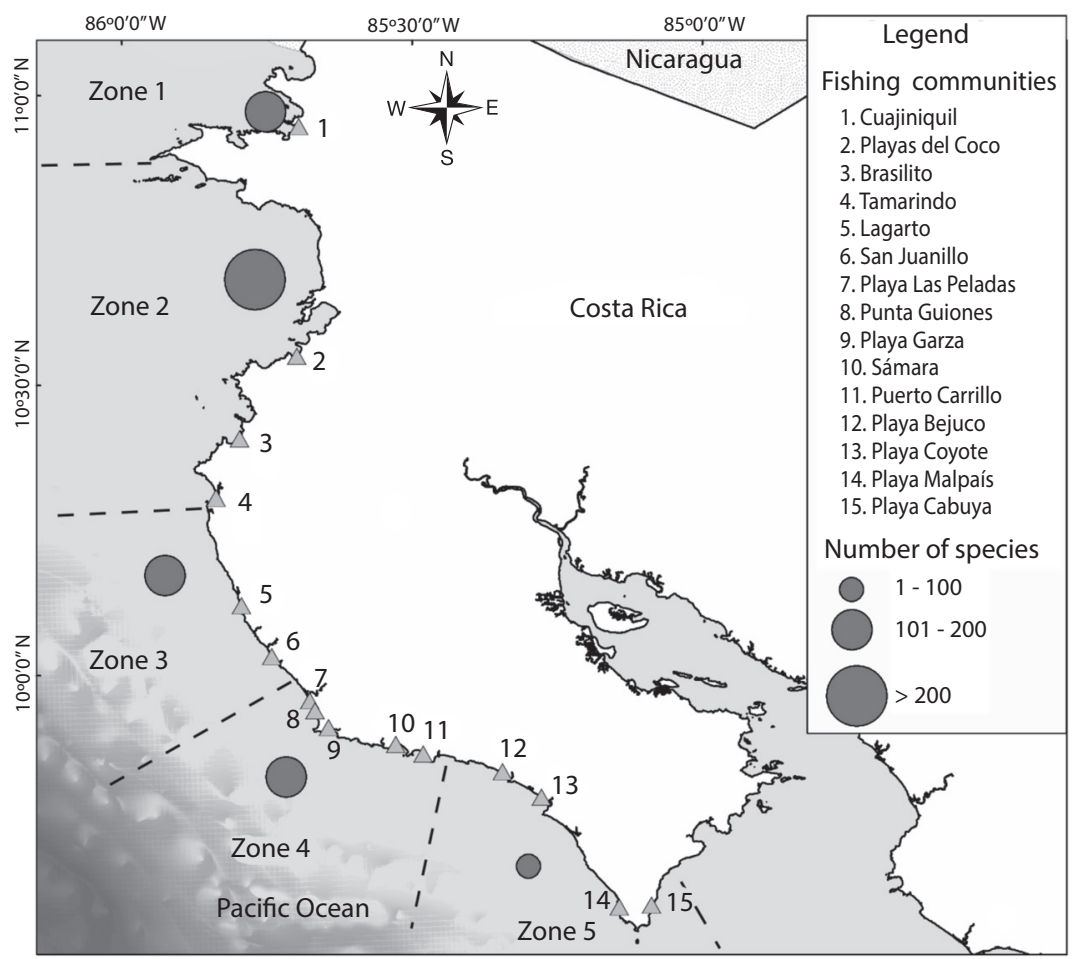

Fig. 2. Número de especies de peces depositados en el Museo de Zoología de la Universidad de Costa Rica, por zona del Pacífico Norte de Costa Rica.

Fig. 2. Number of fish species deposited in the Museo de Zoología of the Universidad de Costa Rica, per zone of the North Pacific, Costa Rica.

de aguas medias (en función a la termoclina) y de aguas superficiales (entre 5 y $10 \mathrm{~m}$ de profundidad) (OSPESCA, 2010).

En el Pacífico Norte las actividades asociadas a la pesca palangrera se desarrollan principalmente en Cuajiniquil y Playas del Coco. En Cuajiniquil existen aproximadamente 20 embarcaciones palangreras. Según los pescadores entrevistados las faenas de pesca duran entre 20 y 30 días; y las especies más capturadas son el dorado: Coryphaena hippurus (Linnaeus, 1758), el tiburón gris o sedoso: Carcharhinus falciformis (Müller \& Henle, 1839), el tiburón martillo: Sphyrna lewini (Griffith \& Smith, 1834), el pez vela: Istiophorus platypterus (Shaw, 1792), el pez espada: Xiphias gladius Linnaeus, 1758, el atún de aleta amarilla: Thunnus albacares (Bonnaterre, 1788) y el atún ojo grande: Thunnus obesus (Lowe,
1839). Especies recibidas en cantidades más bajas pero que también son aceptadas en los recibidores son el marlin rosado: Kajikia audax (Philippi, 1887) y el marlin blanco: Makaira mazara (Jordan \& Snyder, 1901). En Playas del Coco existen varios recibidores de pescado y su flota palangrera captura los mismos recursos que los pescadores de Cuajiniquil, enfocándose a principalmente en el dorado, atún aleta amarilla, pez vela y pez espada.

Esta información coincide con lo reportado para las descargas de pesca de 17 viajes de embarcaciones de Playas del Coco de febrero del 2006 a diciembre de 2007 (Arauz, López \& Zanella, 2007), donde indican que las principales especies objetivo de las flotas palangreras fueron el dorado $(65 \%$ de los individuos descargados) y el grupo de los tiburones (13\%). Dentro del grupo de los tiburones, el tiburón 
gris o sedoso representó el 95\%, mientras que el 5\% restante estuvo compuesto por el tiburón zorro pelágico: Alopias pelagicus (Nakamura, 1935), el tiburón martillo, el tiburón cocodrilo: Pseudocarcharias kamoharai (Matsubara, 1936), el tiburón aleta negra: Carcharhinus limbatus (Müller \& Henle, 1839) y el tiburón zorro ojón: Alopias superciliosus (Lowe, 1841). Algunas especies de menor importancia fueron el pez vela, el marlin blanco, el marlin rosado y varias especies de atún: Thunnus spp.; que representaron el $8 \%, 5 \%, 4 \%$ y $4 \%$ de los individuos descargados respectivamente. El wahoo: Acanthocybium solandri (Cuvier \& Valenciennes, 1832) y el pez espada representaron solamente el $0.6 \%$ de los individuos descargados.

Así mismo, en un programa de monitoreo con observadores a bordo de embarcaciones palangreras nacionales realizado entre 1999 y 2010, se capturó un total 62 especies de peces, tres especies de tortugas marinas (Dermochelys coriacea, Chelonia mydas y Lepidochelys olivacea) y una especie no identificada de delfín (Dapp et al., 2013). Las especies más abundantes en este estudio fueron el dorado con 31.34 capturas/1000 anzuelos, la tortuga lora: Lepidochelys olivacea (Eschscholtz, 1829) con 8.85 capturas/1000 anzuelos, el tiburón gris o sedoso (8.08 capturas/1000 anzuelos), la raya pelágica: Pteroplatytrygon violacea (Bonaparte, 1832) (4.38 capturas/1000 anzuelos) y el pez vela (2.07 capturas/1000 anzuelos).

Pesca artesanal. Esta flota utiliza una gran variedad de artes de pesca que incluyen el trasmallo, la cuerda de mano y la línea planera (PROAMBIENTE, 1999, Ross-Salazar, 2014). La cuerda de mano permite una mayor selectividad de los peces retenidos, de acuerdo al tamaño de anzuelo utilizado (Ross-Salazar, 2014). Las principales especies capturadas con cuerda de mano son corvinas (Sciaenidae) y pargos (Lutjanus spp). La línea planera o palangre de fondo, tiene por objetivo especies de peces demersales, principalmente de zonas rocosas que tienen un alto valor en el mercado, como lo son las cabrillas (Serranidae), los congrios (Ophidiidae) y los pargos (RossSalazar, 2014). El trasmallo o red de enmalle es uno de los artes de pesca menos selectivos, y causa una alta mortalidad de las especies no objetivo. Las principales especies capturadas con este arte son los róbalos (Centropomidae), las corvinas, los jureles (Carangidae) y los roncadores (Haemulidae); mientras como fauna incidental se capturan principalmente tiburones (Ross-Salazar, 2014).

La flota artesanal de Cuajiniquil se compone de aproximadamente 50 pangas que pescan con línea, cuerda, y trasmallo. Según los pescadores entrevistados, las faenas de pesca duran de 4 a 8 días y se realizan desde Puerto Soley (Bahía Salinas) hasta Playa Blanca (Península de Santa Elena). Las carnadas utilizadas son calamar, sardina gallera (Opisthonema spp.) y ballyhoo: Hemiramphus brasiliensis (Linnaeus, 1758). Las principales especies comercializadas son el pargo manchado: Lutjanus guttatus (Steindachner, 1869), los meros: Epinephelus spp., las cabrillas (Epinephelus spp. y Cephalopholis sp.), los roncadores, el dorado, el congrio: Brotula clarkae (Hubbs, 1944) y las corvinas. La cadena de comercialización incluye varios intermediarios. La mayoría de los productos se consumen en el mercado nacional, principalmente en San José, mientras que otros son exportados. Por otro lado, la corvineta (o culebra verde): Cynoponticus coniceps (Jordan \& Gilbert, 1882), el chancho (Balistidae) y el loro: Scarus spp. son capturados con menor frecuencia y consumidos localmente. Según algunos pescadores entrevistados, las capturas de estos grupos presentan patrones estacionales y espaciales co-relacionadas con la temperatura del agua.

En Playas del Coco existe una flota artesanal compuesta por 327 licencias activas. Los pescadores de esta zona enfocan el esfuerzo pesquero áreas costeras, principalmente en Sámara, Nosara, Golfo de Papagayo y la Península de Santa Elena. Esta pesquería selecciona peces de alto valor comercial, principalmente pargo seda: Lutjanus peru (Nichols \& Murphy, 1922), pargo manchado, dorados, meros, corvinas y cabrillas. 
La comunidad pesquera de Puerto Coyote se compone de aproximadamente 19 pangas y 40 pescadores. El arte de pesca utilizado es la línea planera con una línea madre de aproximadamente un kilómetro (entre $600 \mathrm{y}$ 800 anzuelos tipo "J" número 7 y 8 ). Se pesca aproximadamente entre los 5 y $6 \mathrm{~km}$ de la costa, cerca del Río Bongo, Bejuco y ocasionalmente en San Juanillo. Las especies objetivo son el pargo manchado, y pargo cola amarilla: Lutjanus argentiventris (Peters, 1869). Además comercializan la corvina agria: Micropogonias altipinnis (Günther, 1864), el pargo seda, corvina ñata: Larimus spp., el congrio y el tiburón mamón: Mustelus spp. La comercialización se da a través de un intermediario que suple a Productos del Golfo S.A., empresa en Jicaral dedicada a la exportación y venta productos marinos. Además, existen una asociación civil sin fines de lucro, PRETOMA (Programa de Restauración de Tiburones y Tortugas Marinas) y dos asociaciones de pescadores en Puerto Coyote: (1) la Asociación de Pescadores de Coyote (ASPECOY) y (2) la Asociación de Pescadores de Puerto Coyote (ASPEPUCO).

La comunidad pesquera de Bejuco está compuesta por 20 pangas y 40 pescadores. Como arte de pesca, utilizan línea planera con aproximadamente 800 anzuelos tipo "J" número 7 y 8 , y las especies objetivo son las mismas que en Puerto Coyote. El esfuerzo pesquero es mayor que en Puerto Coyote porque utilizan un sistema en que revisan las líneas cada una ó dos horas para recoger las capturas y llenar los anzuelos vacíos con carnada. Tienen una Asociación de Pescadores de Bejuco (ASOBEJUCO). Existen dos intermediarios en Bejuco, uno permanente y uno estacional.

Existe la iniciativa por parte de ASPEPUCO y ASOBEJUCO, con el apoyo de PRETOMA y el financiamiento del Sustainable Fisheries Fund y Conservación Internacional (CI) para mejorar la calidad de vida de los pescadores de la zona. Uno de los proyectos tiene como objetivo obtener una certificación internacional de pesca sostenible (Marine Stewardship Council, MSC) e introducir el producto eco-etiquetado a los hoteles de las comunidades vecinas y restaurantes exclusivos (PRETOMA, 2013). Además, se propone la creación de un área cerrada a la pesca de arrastre entre las áreas marinas protegidas de los Refugios Nacionales de Vida Silvestre Caletas-Arío (creado en 2006) y Camaronal (creado en 2009), para una área total de $19.3 \mathrm{~km}^{2}$ (Soto, 2014).

La comunidad de pescadores de Malpaís está compuesta por aproximadamente 40 personas operando 20 pangas. Utilizan línea planera (de aproximadamente 300 anzuelos tipo $\mathrm{J}$, número 5 y 7), cuerda de mano y trasmallo (2.5-7 cm luz de malla). Según los pescadores de la zona, las faenas de pesca son realizadas durante el día y tienen una duración aproximada de dos a tres horas, con el objetivo de capturar principalmente el pargo (manchado, cola amarilla y seda) y la cabrilla. Al igual que los pescadores de Cuajiniquil, en esta comunidad nos indicaron que existe una estacionalidad marcada en los recursos. Por ejemplo, el pargo manchado se pesca a $11.2 \mathrm{~km}$ de la costa en junio, las cabrillas en el fondo cuando las aguas están frías entre noviembre y marzo, el dorado entre octubre y diciembre, el atún entre mayo y junio y el bolillo (Mustelus spp. Isurus spp, Sphyrna spp. y Carcarhinus spp.) en invierno (entre octubre y diciembre). En Malpaís el producto se vende a los restaurantes de la zona y a las empresas exportadoras en Puntarenas, para el cual dependen de un intermediario.

La pesca artesanal en Cabuya comenzó hace 30 años. Sin embargo, la gran abundancia de pulga de mar (Amphipoda) frente a Cabuya impide que se pesque, ya que éste se come las capturas y la carnada. La comunidad pesquera se compone de aproximadamente 20 pangas cuando la "pesca está buena" y 3 pangas cuando la "pesca está mala". Las artes de pesca que utilizan son línea planera, cuerda y trasmallo. Las especies objetivo son el pargo seda y mancha, la cabrilla, el dorado, congrio y mamón (Mustelus spp.). En los últimos años han observado varias explosiones poblacionales de pargo, cabrilla y congrio, durante las cuales llegan muchos pescadores desde comunidades lejanas como Cuajiniquil y Puntarenas. Esta pesca intensiva continúa hasta que el recurso se vuelve escaso. 
Pesca de arrastre. La pesca de arrastre de camarón, utiliza barcos semi-industriales con dos redes de arrastre de 33 metros de relinga superior y 50 metros de largo (Álvarez \& Ross-Salazar, 2009). La pesca de arrastre en el Pacífico Norte comenzó como resultado de la modernización de la flota, que aumentó la distancia que podían recorrer las embarcaciones entre 1960 y 1979 (Álvarez \& RossSalazar, 2009). Según Villalobos (1983) el camarón café o "brown" (Farfantepenaeus californiensis (Holmes, 1900) (Penaeidae) fue muy abundante en el Pacífico Norte durante la década de 1970, pero en la actualidad los caladeros de la zona se encuentran sobreexplotados (Wehrtmann \& Nielsen-Muñoz, 2009; Fernández-Carvajal, 2013).. Esta pesquería es poco selectiva, con altos porcentajes de fauna de acompañamiento (FACA) en la captura total (Wehrtmann et al., 2011). En el Pacífico Norte de Costa Rica se determinó que el 80,25\% de las capturas de la pesquería del camarón rosado (Farfantepenaeus brevirostris) son FACA (Ross-Salazar, 2014). Para la pesquería de arrastre de aguas profundas se reportaron más de 60 especies de peces como parte de la FACA, que llegan a representar hasta un $40 \%$ de las capturas (Wehrtmann \& Nielsen, 2009; Arana, Wehrtmann, Orellana, Nielsen-Muñoz \& Villalobos-Rojas, 2013). En 2009 habían 46 licencias activas para el pacífico costarricense: 44 para la pesca en aguas someras, 2 para la pesca de profundidad ( $>120 \mathrm{~m}$ de profundidad) (Álvarez \& Ross-Salazar, 2009). En el 2013 la Sala Constitucional de Costa Rica, declaró inconstitucionales los artículos de la Ley de Pesca en donde se autoriza el uso de redes de arrastre para la pesca de camarón. Mediante este fallo se prohíbe la otorgación de permisos, autorizaciones o licencias nuevas, renovación de permisos vencidos o reactivar permisos inactivos para la pesca de camarón con redes de arrastre de fondo (Sentencia No 2013-10540).

Pesca mediante buceo. La pesca mediante buceo se dirige hacia organismos que no son fácilmente accesibles por medio del uso de artes de pesca tradicionales. Se practican principalmente dos tipos de pesca mediante buceo: buceo a pulmón o apnea y buceo con compresor. Estas actividades se realizan hasta los $11 \mathrm{~m}$ y $40 \mathrm{~m}$ de profundidad respectivamente (Naranjo, 2010). El buceo con compresor y buceo a pulmón están dirigidos a la captura de invertebrados tales como: langostas, pulpos, ostiones, cambutes, y pepinos de mar, así como sobre peces ornamentales para acuario y especies de consumo (Dominici-Arosemena, 1999; Arroyo-Mora, 2008; Naranjo, 2010). En ambas modalidades de pesca mediante buceo se usan arbaletas, redes y bicheros (Arroyo-Mora, 2008; Naranjo, 2010, Ross-Salazar, 2014).

La extracción de peces ornamentales comenzó en la década de 1980, pero se comenzó a regular partir de 1989 (Decreto 19450MAG) (Fournier, 2004; Espinoza-Mendiola $\&$ Nielsen-Muñoz 2007). En este decreto se determinaron tres zonas de extracción de peces de acuario para el Pacífico Norte (Zona 1: del límite de Costa Rica con Nicaragua hasta Cabo Santa Elena, Zona 2: de cabo Santa Elena hasta Punta Guiones, y Zona 3: de Punta Guiones hasta Cabo Blanco). Se permite 20 permisos por zona, con una captura máxima de 1000 individuos de cada especies por mes (individuos/especie/mes), exceptuando las Zonas 1 y 3 donde se permite 10 permisos por zona, con una captura máxima de 500 individuos/ especie/mes. Esta ley afirma que dichas cuotas fueron impuestas arbitrariamente debido a la falta de conocimiento biológico de las especies objetivo.

En Playas del Coco, Brasilito y Cuajiniquil, se capturan principalmente 20 especies de peces ornamentales (Fournier, 2004). Entre los más comunes están el pez ángel: Holacanthus passer Valenciennes, 1846, ángel de Cortés: Pomacanthus zonipectus (Gill, 1862), halcón de coral: Cirrhitichthys oxycephalus (Bleeker, 1855), narizón: Oxycirrhites typus Bleeker, 1857, mejicana (fase inicial) y cabeza azul (fase terminal): Thalassoma lucasanum, (Gill, 1862), pez puercoespín: Diodon holocanthus Linnaeus, 1758, pez erizo pecoso: Diodon hystrix Linnaeus, 1758, timboril: Arothron meleagris (Lacépède, 1798) y cardenal: Apogon dovii 
Günther, 1862) (Dominici-Arosemena, 1999, Fournier, 2004).

Un caso especial es el de T. lucasanum, que sufre doble presión debido a que el comercio y la regulación se da por nombre común (mejicana y cabeza azul). Se determinó que $T$. lucasanum presentaba densidades y tallas más pequeñas en arrecifes cercanos a pueblos pesqueros, que dentro de de los arrecifes protegidos del ACG (McCauley, Joyce \& Lowenstein, 2008). Las poblaciones de peces ángel y el pez puercoespín también han disminuido desde la década de 1990 (Dominici-Arosemena, 1999).

Pesca turística. La pesca turística tiene como objetivo capturar grandes pelágicos. En este arte de pesca se utilizan anzuelos circulares con reinal de monofilamento, y el método de curricán (Ross-Salazar, 2014). Se promueve la modalidad de "pesque-libere", que consta en liberar en el menor tiempo y con el menor daño posible, los ejemplares de peces después de haber sido capturados con vida (Fundación MarViva, 2010). Se prohíbe la comercialización de las capturas obtenidas de esta pesca (FAO 2004, Fundación MarViva 2010, RossSalazar, 2014)

La pesca turística ha crecido en el Pacífico de Costa Rica, principalmente en Flamingo, Guanacaste, Marina los Sueños, Quepos, y Golfito, Puntarenas (FAO, 2006). En los años 1995, 1997 y 1998 el porcentaje de turistas que ingresaron a Costa Rica atraídos por esta actividad varió entre 6.0 y 6.7\% (Morera-Beita, 2001), aumentando a un $20.1 \%$ para el 2008 (IICE, 2010). Costa Rica es considerado uno de los mejores destinos para la pesca turística y deportiva (Holland, Ditton \&. Graefe, 1998; Beltrán-Turriago, 2001).

Las especies de mayor interés en la pesca turística en el Pacífico Norte son el wahoo: Acanthocybium solandri (Cuvier, 1832), atún aleta amarilla, pez gallo: Nematistius pectoralis (Gill, 1862), dorado o mahi-mahi y los picudos (marlin blanco, marlin rosado y pez vela). En el 2008 las especies más capturadas fueron el pez vela, el marlin y el dorado (IICE, 2010). A pesar de ser capturadas a lo largo del año, los comerciantes indican que las capturas varían estacionalmente. Debido a las características migratorias y poblacionales de los picudos, muchas especies poseen medidas de protección internacional y/o nacional (Cuadro 2).

En las zonas con gran desarrollo hotelero del Pacífico Norte como el Golfo de Papagayo, Playa Carrillo, Montezuma y Flamingo existen más empresas que ofrecen servicios de pesca turística. La mayoría de estas empresas también ofrecen las actividades recreativas de snorkel y buceo, siendo los principales destinos Isla Cabo Blanco, Islas Catalinas e Islas Murciélago.

Según INCOPESCA (Playas del Coco), a principios del 2012 existían 146 licencias para pesca turística inscritas solo en Playas del Coco, para embarcaciones con gran variabilidad en nacionalidad, capacidad máxima (6-27 personas) y usos (buceo y snorkel, pesca comercial, pesca turística). En zonas con menos desarrollo turístico, esta pesca se da a menor escala. Por ejemplo, en Malpaís los pescadores artesanales ofrecen servicios de pesca turística con las mismas embarcaciones con las que practican la pesca artesanal.

\section{Estadísticas de descargas de INCOPES-}

CA. Según las estadísticas de descargas para la zona de Guanacaste, las clases comerciales más abundantes entre 1990 y 2009 fueron el dorado y los tiburones (Figs. 3-5). Estas descargas han presentado una tendencia decreciente, más notoria para las descargas del dorado que alcanzaron un pico en el 2001 disminuyendo drásticamente para el 2004 (Fig. 3). Según el Estado de la Nación (2002), los tiburones representaron el 58\% de las descargas en el Pacífico Norte entre 1988 y 1997, pero a partir del año 2000, las descargas de este grupo comenzaron a disminuir drásticamente. Asimismo, los desembarques reportados para varias especies de picudos (marlin blanco, marlin rosado, pez vela y pez espada) por la flota palangrera, han mantenido una ligera tendencia decreciente (Fig. 4).

Las estadísticas de descargas de la flota artesanal sugieren que la mayoría de los 


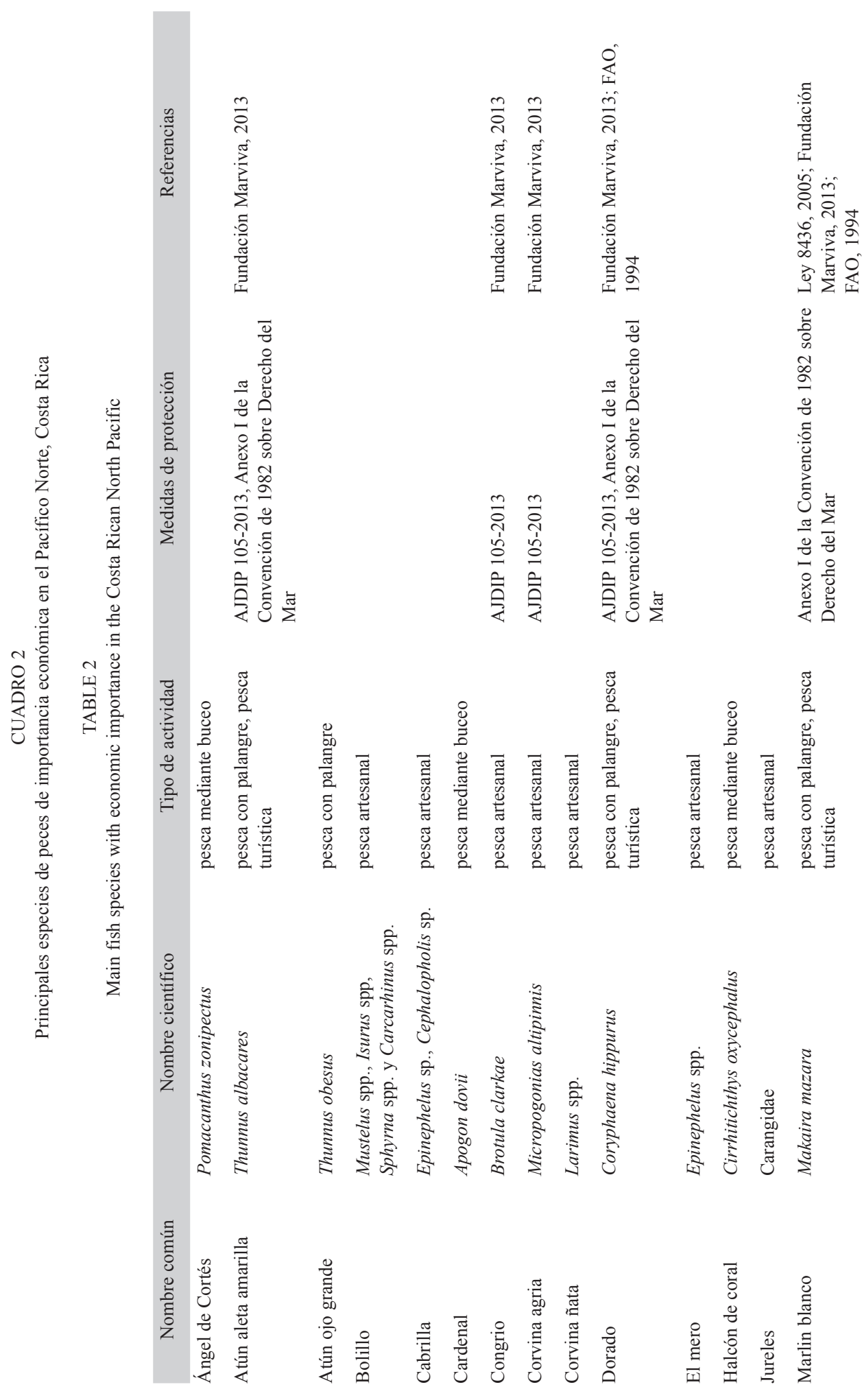




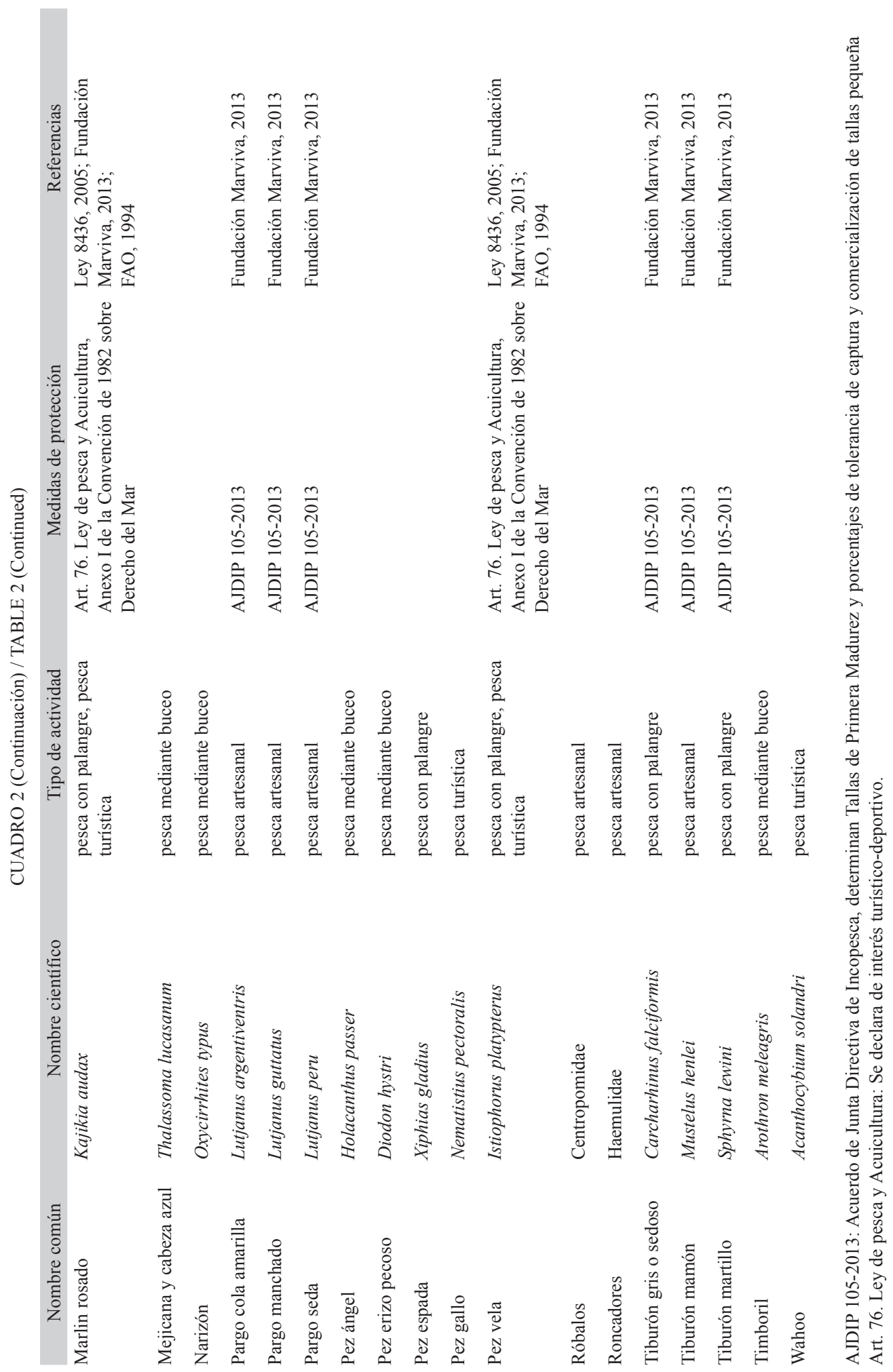




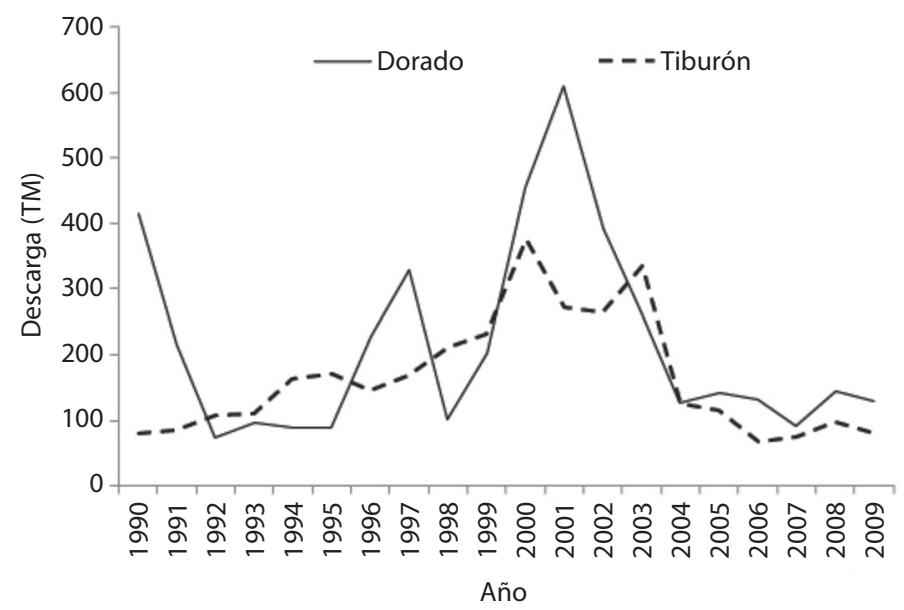

Fig. 3. Descargas de principales especies de peces pelágicos obtenidas por las flotas palangrera y artesanal en el Pacífico Norte, Costa Rica durante el periodo 1990-2009 (INCOPESCA, 2014).

Fig. 3. Landings of main pelagic fish species obtained by the artisanal and longline fleets in the North Pacific, Costa Rica during the period 1990-2009 (INCOPESCA, 2014).

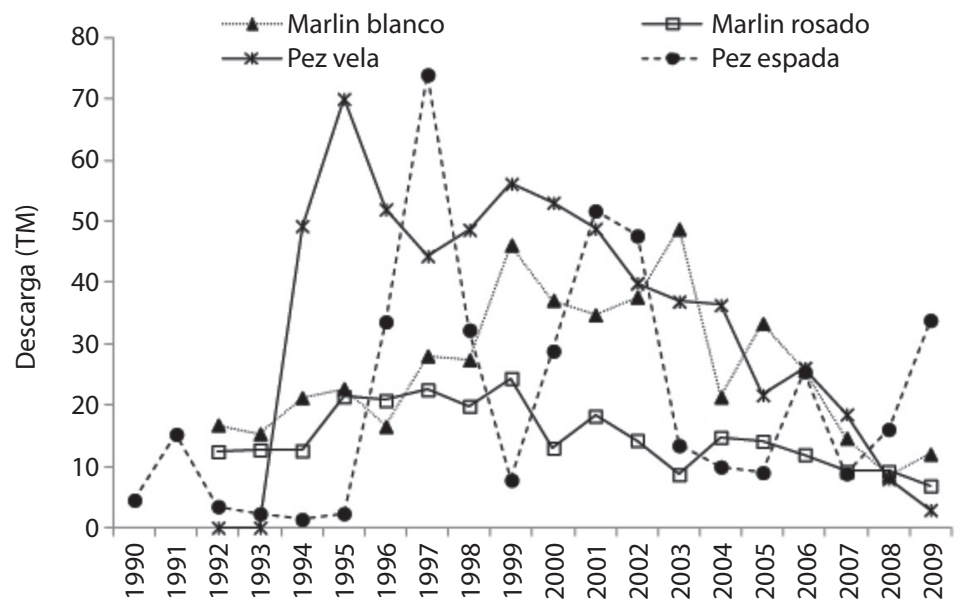

Año

Fig. 4. Descargas de principales especies de peces pelágicos capturados por la flota palangrera en el Pacífico Norte, Costa Rica durante el periodo 1990-2009. Especies de marlín tienen información a partir del 1991 (INCOPESCA, 2014).

Fig. 4. Landings of main pelagic fish species obtained by the longline fleet in the North Pacific, Costa Rica during the period 1990-2009. Marlin species have information starting the year 1991 (INCOPESCA, 2014).

recursos pesqueros presentan una tendencia de disminución. Las descargas de especies objetivo en la pesca artesanal, como la cabrilla y el pargo seda, han disminuido desde 1991 (Fig. 5). Adicionalmente, Gutiérrez-Vargas (1990) determinó que el pargo seda se sobreexplotó en la década de 1980, cuando era uno de los recursos más importantes para la pesca artesanal en el Pacífico Norte.

Conflictos entre actividades. Se detectaron conflictos entre diversas actividades debido 

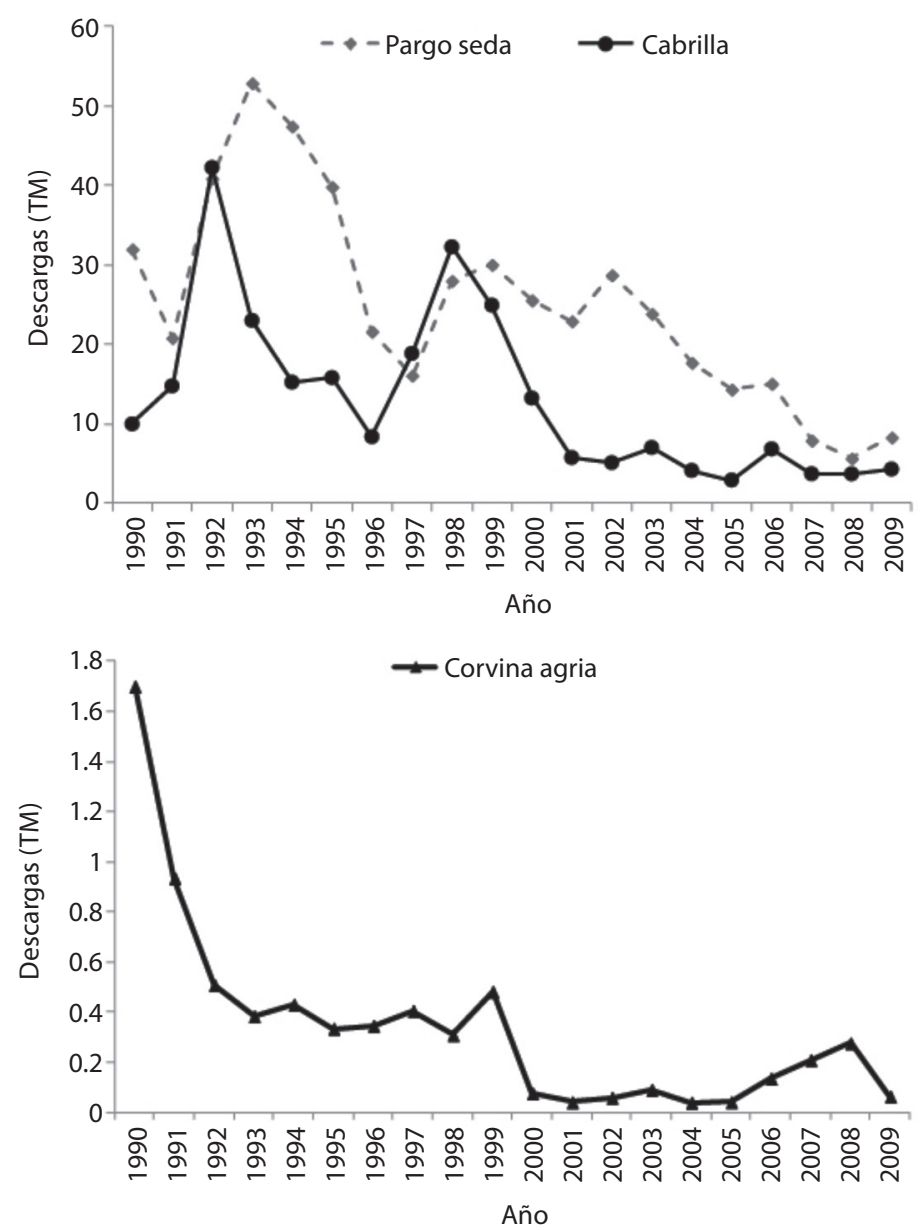

Fig. 5. Descargas de principales especies de peces demersales capturados por la flota artesanal en el Pacífico Norte, Costa Rica durante el periodo 1990-2009 (INCOPESCA, 2014).

Fig. 5. Landings of main pelagic fish species obtained by the artisanal fleet in the North Pacific, Costa Rica during the period 1990-2009 (INCOPESCA, 2014).

a la competencia entre los recursos marinos. Los conflictos más recurrentes mencionados por las personas entrevistadas fueron: (1) la pesca turística con la pesca con palangre, (2) el buceo recreativo con la pesca mediante buceo, (3) la flota artesanal con la flota camaronera y (4) entre artesanales de otras zonas del Pacífico.

Pesca turística con la pesca con palangre: Los pescadores turísticos consideran a la pesca con palangre y a la pesca artesanal de peces pelágicos como actividades que afectan negativamente la disponibilidad de recursos pelágicos debido a su carácter extractivo. En el país se declararon de interés turístico-deportivo al "pez vela (Istiophorus albidius), marlin azul (Makaira nigrioans), marlin negro (Makaira indica), marlin rallado (Tetrapturas audaz) y sábalo (Melaops atlanticus)" (Ley 8436, 2005). Adicionalmente, al capturarse una especie de picudo por pescadores deportivos y turísticos, o incidentalmente por parte de pescadores comerciales no turísticos y el pez esté aún con vida, éste deberá ser liberado cortando el reinal o la línea lo más cercano posible del anzuelo, sin sacar del agua el espécimen capturado (Fundación Marviva, 2013). Asimismo, se prohíbe a 
las embarcaciones de pesca turística-deportiva colocar, sobre la borda, los ejemplares capturados para efectos fotográficos y el uso de bicheros o ganchos para arrimar los ejemplares de picudos capturados (Cajiao-Jiménez, 2010; Fundación Marviva, 2013)

Es importante mencionar que a pesar de que la pesca turística se promueve internacionalmente como una actividad no extractiva, en la mayoría de los casos en los lugares visitados este servicio no fue ofrecido como "pesque y libere". Además, la ausencia de estadísticas pesqueras sobre el porcentaje de peces capturados en la pesca turística dificulta estimar su impacto sobre las mismas.

\section{Buceo recreativo con la pesca mediante}

buceo: Los operadores de buceo de Playas del Coco y Ocotal señalaron un conflicto con las actividades de pesca mediante buceo, debido a que ambas actividades pueden realizarse en los mismos sitios. En muchas ocasiones los usuarios de buceo recreativo se llevan una mala impresión al ver a los pescadores extrayendo diferentes tipos de organismos (Jiménez, 1997). Asimismo, desde 1994 la disminución de las poblaciones de peces de arrecife y el deterioro de las poblaciones de peces ornamentales ha sido motivo de preocupación entre grupos dedicados al buceo recreativo (Fournier, 2004, ; Espinoza \& Nielsen, 2006; Ibarra-Gene, 2006). INCOPESCA ha comenzado a implementar nuevas licencias de pesca submarina en Playa del Coco, para buzos con compresor y buceo a pulmón con el fin de que reporten sus capturas y aumentar el nivel de control. Sin embargo, la información sobre capturas por zona y por especie registradas en las oficinas regionales, principalmente Guanacaste, no ha sido procesada en el INCOPESCA, indicando un control exiguo de esta pesquería (Fournier, 2004). Por otro lado, la pesca mediante buceo es una actividad que genera pocos ingresos a los pescadores (Ibarra-Gene, 2006). Se determinó que los peces de arrecife del Golfo de Papagayo tienen mayor valor con fines recreativos que con fines extractivos (Fournier, 2004).

Pesca de arrastre y pesca artesanal: Además de que a pesca de arrastre presenta altos porcentajes de fauna de acompañamiento (FACA) en la captura total (Wehrtmann et al., 2011), en la actualidad los caladeros de camarón se encuentran sobre-explotados (Wehrtmann \& Nielsen-Muñoz, 2009; Fernández-Carvajal, 2013). Como medida para aumentar los ingresos de la pesquería de arrastre, en ocasiones la pesca se dirige a capturar peces de valor comercial (Álvarez \& RossSalazar, 2009). Esto ha generado un problema social y económico a lo largo de la costa del Pacífico al eliminar el recurso del cual dependen miles de pescadores artesanales.

Pescadores artesanales: Debido a la sobre pesca de los recursos, pescadores artesanales que típicamente faenan en el Golfo de Nicoya, navegan al Pacífico Norte a pescar principalmente en la zona sur de la península de Nicoya.

\section{RECOMENDACIONES}

Según el número de publicaciones, los registros y el número de especies de peces presentes en la base de datos del Museo de Zoología, la zona mejor estudiada en cuanto a diversidad de especies es el Golfo de Papagayo. Futuros estudios deberían enfocarse en zonas con pocos registros de especies, como la zona entre Puerto Carrillo y Montezuma.

Creemos necesaria una revisión detallada de la Ley de Pesca y Acuicultura $\left(\mathrm{N}^{\circ}\right.$ 8436), ya que encontramos errores ortográficos importantes. Por ejemplo, cuatro de las cinco especies declaradas de interés para la pesca turística-deportiva (Art. 76) no existen en las bases internacionales como FishBase (http:// www.fishbase.org) y Worms (http://www. marinespecies.org). Suponemos que están mal escritas, y que deberían leerse de la siguiente manera (nombre en la Ley: nombre correcto): el pez vela Istiophorus albidius: Istiophorus platypterus (Latreille, 1804), el marlín azul Makaira nigrioans: Makaira nigricans Lacepède, 1802, el marlin rallado Tetrapturas audaz: Tetrapturus audax, ahora Kajikia audax (Philippi, 1887) y el sábalo Melaops atlanticus: Megalops atlanticus Valenciennes, 1847. 
Las estadísticas pesqueras de INCOPESCA deben interpretarse con precaución. Los registros de descargas no incluyen el esfuerzo pesquero de las diferentes flotas. Por lo tanto, las tendencias encontradas podrían reflejar variaciones en el esfuerzo y el comportamiento de la flota, en vez de la abundancia del recurso. Además, es necesario que las descargas se registren por especie y no por clases comerciales. Estas estadísticas también debería tomar en cuenta los porcentajes de FACA liberados y capturados por cada tipo de pesquería. Cada especie presenta distintas tasas de crecimiento poblacional, por lo tanto, la mortalidad por pesca que una especie puede tolerar también varía.

Las tallas de primera madurez (TPM) han sido estimadas para algunas especies de dorado, pargo y tiburón. También se han establecido los porcentajes de tolerancia de captura que permite la comercialización de tallas menores a la TPM (Cuadro 2) (Fundación Marviva, 2013). El cumplimiento de estas regulaciones podría ser verificado mediante el monitoreo de la cantidad extraída y talla por especie en todas las fases productivas, desde la descarga, al transporte, acopio, procesamiento y comercialización. Aún si este sistema de monitoreo se llegara a establecer, las tallas mínimas de captura y los porcentajes de tolerancia de capturas de tallas bajo TPM se ha estimado para muy pocas especies. Asimismo, existe falta de información para establecer los límites de captura para todas las especies comerciales. Por ejemplo, los límites de capturas de peces ornamentales fueron establecidos arbitrariamente producto de la falta de información. Para evitar el agotamiento de los recursos pesqueros es necesario definir y aplicar el nivel de explotación que permite obtener el rendimiento máximo del "stock" a largo plazo. Este nivel de explotación se determina a partir de datos biológicos-pesqueros: zonas de pesca, esfuerzo pesquero (número de embarcaciones, intensidad de pesca), biomasa capturada por especie, así como su estructura de tallas, proporción sexual, fecundidad, reclutamiento, tasas de crecimiento (Sparre \& Venema, 1997).
La pesca mediante buceo dirigida a peces de consumo humano no está regulada en la zona, ni existen registros o estadísticas de capturas. Con el objetivo de documentar y regular estas capturas, INCOPESCA está implementando licencias de pesca submarina en Playas del Coco. Sin embargo, no es recomendable que se pongan en vigencia hasta que se determine la viabilidad de esta pesquería, las especies permitidas y regulaciones de captura. Implementar estas licencias sin una línea base podría llevar al colapso de estos recursos, ya que esta pesca es selectiva y captura organismos vulnerables a la presión pesquera, como la poca movilidad (ej. pepinos de mar y moluscos) o hermafroditismo secuencial (ej. peces loro y cabrillas).

El Ministerio Nacional de Ambiente, Energía y Telecomunicaciones (MINAET) e INCOPESCA estiman que las poblaciones de peces objetivo de la pesca turística están en buenas condiciones, a pesar del incremento en tamaño de la flota y de que los registros de capturas insuficientes o inexistentes (Beltrán-Turriago, 2001). Es necesario evaluar el estado real de las poblaciones de las especies objetivo debido al alto grado de traslape de recursos entre la pesca turística y la pesca de palangre, principalmente del pez vela y marlin (Ditton \& Grimes, 1995).

La búsqueda de una certificación para sus productos (MSC) y el interés de crear zonas de pesca regulada (AMPR-San Juanillo y la propuesta para la creación de un área cerrada a la pesca de arrastre por la comunidad de Coyote), son algunas de las medidas perseguidas por pescadores de comunidades del Pacífico Norte. Estas iniciativas demuestran que en el Pacífico Norte hay interés de los pescadores por regular su recurso.

\section{AGRADECIMIENTOS}

Se agradece a la Agencia Alemana de Cooperación GiZ a través del Proyecto BIOMARC por el apoyo económico y a la Asociación Costa Rica por Siempre. A la Vicerrectoría de Investigación de la Universidad de Costa Rica a través del proyecto 808-B2-400. A Arturo 
Angulo Sibaja y al Museo de Zoología por facilitarnos la base de datos del Museo de Zoología de la Universidad de Costa Rica. A PRETOMA por su colaboración con el proyecto, a Andrea Rodríguez por su ayuda en el trabajo de campo, a Wendy Tayler por su apoyo en logística y a los pescadores de las comunidades que amablemente colaboraron con nosotros.

\section{RESUMEN}

El Pacífico Norte (PN) costarricense alberga una gran diversidad de peces. Esta diversidad sustenta dos de las principales actividades económicas desarrolladas en el PN: pesca y turismo. El presente trabajo caracteriza las actividades dependientes de la ictiofauna del PN. Se sintetizó la información recopilada mediante: encuestas semi-estructuradas con actores involucrados en el uso de la ictiofauna; análisis de las bases de datos del Museo de Zoología - Universidad de Costa Rica e INCOPESCA; y una revisión bibliográfica. Se registraron 424 especies de peces en el PN. Las especies objetivo de cada pesquería son: el dorado, tiburón sedoso, tiburón martillo, atún, pez vela y pez espada en la pesca de palangre; los pargos, las corvinas, robalos y meros en la pesca de artesanal; invertebrados, peces ornamentales en la pesca por buceo; camarones en la pesca de arrastre; y wahoo, atún aleta amarilla, pez gallo, dorado y picudos en la pesca turística. El traslape en el uso de los recursos sumado al agotamiento de los recursos pesqueros está provocando conflictos entre los diferentes sectores que aprovechan la diversidad de peces en el PN. Como consecuencia, es urgente implementar estrategias de manejo que aseguren el aprovechamiento sostenible de los recursos marino-costeros del PN.

Palabras clave: peces, artisanal; palangre; turismo; buceo, pesquerías.

\section{REFERENCIAS}

Arana, P.M, Wehrtmann, I.S., Orellana, J.C., NielsenMuñoz, V. \& Villalobos-Rojas, F. (2013). By-catch associated with fisheries of Heterocarpus vicarius (Costa Rica) and Heterocarpus reedi (Chile) (Decapoda: Pandalidae): A six-year study (2004-2009). Journal of Crustacean Biology 33(2), 198-209.

Alvarado J. J., Herrera, B., Corrales, L., Asch, J. \& Paaby, P. (2011). Identificación de las prioridades de conservación de la biodiversidad marina y costera en Costa Rica. Revista de Biología Tropical, 59, 829-842.

Álvarez, J. \& Ross-Salazar, E. (2009). La pesca de arrastre de Costa Rica. San José: Fundación MARVIVA. San José, Costa Rica.
Arauz, R., López, A \& Zanella, I. (2007). Análisis de la descarga anual de tiburones y rayas en la pesquería pelágica y costera del Pacífico de Costa Rica (Playas del Coco, Tárcoles y Golfito). (Informe final). San José: Conservación Internacional.

Arroyo-Mora, D. (2008). Características poblacionales del cambute, Strombus galeatus (Gastropoda: Strombidae) en el Parque Marino Ballena, Pacífico, Costa Rica (1999-2003). Revista de Biología Tropical, 56 (Supl. 4), 113-124.

Beltrán-Turriago, C.S. (2001). Promoción de la ordenación de la pesca costera: aspectos socioeconómicos y técnicos de la pesca artesanal en El Salvador, Costa Rica, Panamá, Ecuador y Colombia. FAO Circular de Pesca No. 957/2 FIPP/C957/2, Roma, Italia.

Bussing, W.A \& López, M. (2009). Marine Fish. En: Wehrtmann, I.S. \& Cortés, J. (Eds), Marine Diversity of Costa Rica, Central America (pp. 453-458). Berlin: Springer.

Cajiao-Jiménez, M. V. (2010). Manual de legislación marino costera y pesquera de Costa Rica. Fundación MarViva. San José, Costa Rica.

Cortés, J. (1996-1997). Comunidades coralinas y arrecifes del Área de Conservación Guanacaste, Costa Rica. Revista de Biología Tropical, 4 (3)/45(1), 623-625.

Cortés, J. (2012a). Historia de la investigación marinocostera en Bahía Culebra, Pacífico Norte, Guanacaste, Costa Rica. Revista de Biología Tropical, 60 (Supl. 2), 19-37.

Cortés, J. (2012b). Bibliografía anotada sobre organismos, ambientes y procesos marinos en Bahía Culebra, Guanacaste, Costa Rica. Revista de Biología Tropical, 60 (Supl. 2), 231-242.

Cortés, J. \& Wehrtmann, I.S. (2009) Diversity of marine habitats of the Caribbean and Pacific of Costa Rica En: Wehrtmann, I.S. \& Cortés, J. (Eds), Marine Diversity of Costa Rica, Central America (pp. 1-45). Berlin: Springer.

Cortés, J., Vargas-Castillo, R. \& Nivia-Ruiz, J. (2012) Marine biodiversity of Bahía Culebra, Guanacaste, Costa Rica: published records. Revista de Biología Tropical, 60 (Supl. 2), 39-71.

Dapp, D., Arauz, R., Spotila, J. R. \& O’Connor, M.P. (2013). Impact of Costa Rican longline fishery on its bycatch of sharks, stingrays, bony fish and olive ridley turtles (Lepidochelys olivacea). Journal of Experimental Marine Biology and Ecology, 448, 228-239.

Decreto $N^{\circ}$ 19450-MAG (1989) Zonas de Pesca de Peces de Arrecife Descargado de http://www.gaceta.go.cr/

Ditton, R.B. \& Grimes, S. (1995). A social and economic study of the Costa Rica recreational billfish fishery. (Informe para The Billfish Foundation). Florida: The Billfish Foundation. 
Dominici-Arosemena, A. (1999). Estructura poblacional de los peces de arrecifes del Golfo de Papagayo, Guanacaste, Costa Rica, con énfasis en las especies de mayor importancia comercial como ornamentales. Tesis de Maestría, Universidad de Costa Rica, San Pedro, Costa Rica.

Dominici-Arosemena, A., Brugnoli-Olivera, E., CortésNúñez, J., Molina-Ureña, H., \& Quesada-Alpízar, M. (2005). Community structure of eastern Pacific reef fishes (Gulf of Papagayo, Costa Rica). Tecnociencia, 7(2), 19-41.

Ehrhardt, N.M. \& Fitchett, M.D. (2006). On the seasonal dynamic characteristics of the sailfish, Istiophorus platypterus, in the eastern pacific off Central America. Bulletin of Marine Science, 79, 589-606.

Espinoza-Mendiola, M. \& Nielsen-Muñoz, V. (2006). Capítulo VII, Especies Comerciales I: Peces. En Nielsen-Muñoz, V. \& Quesada-Alpízar, M. (Eds.). Ambientes Marino Costeros de Costa Rica. (pp 87-104). Comisión Interdisciplinaria Marino Costera de la Zona Económica Exclusiva de Costa Rica, Informe Técnico. CIMAR, CI, TNC, San José, Costa Rica.

Espinoza, M. \& Salas, E. (2005). Estructura de las comunidades de peces de arrecifes en las Islas Catalinas y Playa Ocotal, Pacífico Norte de Costa Rica. Revista de Biología Tropical, 53, 523-536.

Estado de la Nación. (2002). Capítulo 4: Armonía con la naturaleza. Octavo Informe Estado de la Nación en Desarrollo Humano Sostenible. San José, Programa Estado de la Nación.

FAO (1994). World Review of Highly Migratory Species and Straddling Stocks. FAO Fisheries Technical Paper. Rome.

FAO (2004). Información sobre la ordenación pesquera de la República de Costa Rica. Descargado de http:// www.fao.org/fi/oldsite/FCP/es/cri/body.htm

FAO (2006). Documentos presentados en el Taller regional FAO/OSPESCA sobre el mejoramiento de los sistemas de información y recolección de datos pesqueros para América central y el Caribe. San Salvador, El Salvador, 23-26 de enero de 2006. Informe de Pesca y Acuicultura No 919 Supl. Rome, 149p.

Fernández-Carvajal D. (2013). Pesca artesanal y pobreza en comunidades aledañas al Golfo de Nicoya. Revista de Ciencias Sociales 140, 137-152.

Fournier, M.L. (2004). La Zona Marino-Costera. Décimo Informe Estado de la Nación. San José, Programa Estado de la Nación y Biosfera Consultores S.A./ IRET-UNA.

Fundación MarViva (2010). Así es la pesca deportiva y turística en Costa Rica. San José, Costa Rica.

Fundación Marviva (2013). Compendio de Normas Pesqueras de Costa Rica. San José, Costa Rica.
Gutiérrez-Vargas, R. (1990). Tasas de crecimiento, mortalidad, reclutamiento, rendimiento y biomasa relativos por recluta de Lutjanus peru (Perciformes: Lutjanidae) en el Pacífico Noroeste de Costa Rica. Revista de Biología Tropical, 38, 441-447.

Holland, S.M., Ditton, R.B. \&. Graefe, A.R. (1998). An ecotourism perspective on billfish fisheries. Journal of Sustainable Tourism 6, 1-20.

Ibarra-Gene, E. (2006). El valor de uso del paisaje submarino en el Golfo de Papagayo: comparación de la industria de buceo deportivo con la industria de extracción de peces de acuario. Tesis de Licenciatura, Universidad de Costa Rica, San Pedro, Costa Rica.

IICE (2010). Un análisis de la contribución económica de la pesca deportiva y comercial a la economía de Costa Rica. Universidad de Costa Rica. 166 p.

INCOPESCA (2014). Estadística. Descargado de http:// www.incopesca.go.cr/publicaciones/estadisticas.html

Jiménez, C.E. (1997). Corals and coral reefs of Culebra Bay, Pacific coast of Costa Rica: Anarchy in the reef. Proceedings of the 8th International Coral Reef Symposium, Panamá, 1, 329-334.

Jiménez, J. (2013). Problemática marino-costera en Costa Rica y necesidad de planificación. Ambientico, 250251, 4-8.

Ley 8436 (2005). Ley de Pesca y Acuicultura. Descargado de http://www.gaceta.go.cr/

McCauley, D. J., Joyce, F. J. \& Lowenstein, J. H. (2008). Effects of the aquarium fish industry in Costa Rica on populations of the Cortez rainbow wrasse Thalassoma lucasanum. Ciencias Marinas, 34, 445-451.

Morera-Beita, C.M. (2001). El desarrollo turístico de Costa Rica: un modelo en conformación. Revista GeoNotas, 5(2), 241-245.

Nanne, H. (2003). Costa Rica. Descargado en http://www. fao.org/3/a-a1465e/a1465e11.pdf

Naranjo, H. (2010). Caracterización de los sistemas operacionales, modalidades y artes de pesca utilizados para la captura de la langosta Panulirus gracilis Streets, 1871 en Guanacaste, Costa Rica. Revista de Ciencias Marinas y Costeras, 2, 73-82.

Nielsen-Muñoz, V; Quesada-Alpízar, MA. (eds.). 2006. Ambientes Marino-costeros de Costa Rica. Informe Técnico. San José, CR, Comisión Interdisciplinaria Marino Costera de la Zona Económica Exclusiva de Costa Rica. 219 p.

OSPESCA (2010). La pesca con palangre y la pesca deportiva en Centroamérica. Descargado de http:// www.sica.int/ospesca/

PROAMBIENTE (1999). Diagnóstico de la pesca del tiburón en Centro América. (Informe final). San José, Costa Rica: BID-CMAR. 
Pennington, J.T., Mahoney, K.L.,Kuwahara, V.S., Kolber, D.D., Calienes, R. \& Chavez, F.C. (2006) Primary production in the eastern tropical Pacific: A review Progress in Oceanography, 69, 285-317.

PRETOMA (2013). Los pescadores artesanales de pequeña escala venden pescado de alta calidad a un restaurante de San José. Descargado de http://www. pretoma.org/es/small-scale-artisanal-fishers-sellhigh-quality-fish-to-san-jose-restaurant

Ross-Salazar, E. (2014). Artes, métodos e implementos de pesca. Fundación MarViva, San José, Costa Rica. $86 \mathrm{p}$.

Ross-Salazar, E., Posada, J.M., Melo, G., Suárez, C. \& Ventura-Pozuelo, A.E. (2014). Guía de identificación: peces de importancia comercial en la costa Pacífica de Costa Rica. Fundación MarViva. San José, Costa Rica.

Sentencia No 2013-10540 (2013). Sala Constitucional prohíbe el uso de redes de arrastre para la pesca de camarón. Descargado de http://sitios.poder-judicial. go.cr/salaconstitucional/comunicados/COMUNICADOS\%202013/SC-CP-30-13.htm

SINAC (2009a). IV Informe de País al Convenio sobre la Diversidad Biológica. GEF-PNUD, Oficina de Cooperación y Proyectos-SINAC. Mimeografiado.

SINAC (2009b). Grúas II. Propuesta de ordenamiento territorial para la conservación de la biodiversidad de Costa Rica. Análisis de vacios de conservación en Costa Rica. San José, Costa Rica: Asociación Conservación de la Naturaleza.

SINAC (2010). Politicas para las Áreas Silvestres Protegidas (ASP) del Sistema Nacional de Áreas de Conservación (SINAC) 2011-2015. San José, Costa Rica: MINAE.
Solano, H. (2014). Unas 100.000 hectáreas marinas del Pacifico se integran a red de pesca artesanal sostenible. Descargado de http://www.nacion.com/ vivir/ambiente/hectareas-Pacifico-integran-artesanalsostenible_0_1423257882.html

Soto M. (2014). Pescadores artesanales luchan por primera zona de pesca sostenible. Descargado de http:// www.nacion.com/vivir/ambiente/Pescadores-artesanales-luchan-primera-sostenible_0_1396860345.html

Sparre, P. \& Venema, S.C. (1997). Introducción a la evaluación de recursos pesqueros tropicales. Parte 1. Manual. FAO Documento Técnico de Pesca. $\mathrm{N}^{\circ}$ 306.1 Rev. 2: 420 pp.

Tabash-Blanco, F.A. (2007). Explotación de la pesquería de arrastre de camarón durante el período 1991-1999 en el Golfo de Nicoya, Costa Rica. Revista de Biología Tropical, 55, 207-218.

Villalobos, F.A. (1983). Características del sector pesquero de Costa Rica. Agronomía Costarricense, 7, 77-89.

Wehrtmann, I.S. \& Nielsen-Muñoz, V.(2009). The deepwater fishery along the Pacific coast of Costa Rica, Central America. Latin American Journal of Aquatic Research, 37, 543-554.

Wehrtmann, I.S., Benavides, C., Clarke, T., Espinoza, M., Herrera, J., Nielsen, V., Nivia, J., Romero, R., Villalobos, F. \& Villegas, E. (2011). Los recursos de aguas profundas del Pacífico de Costa Rica: monitoreo 2009-2011. (Informe técnico final) San José, Costa Rica: Universidad de Costa Rica; Centro de Investigación en Ciencias Marinas y Limnología; Unidad de Investigación Pesquera y Acuacultura; Fundación MarViva, The Rainbow Jewels S.A.

Whoriskey, S., Arauz, R. \& Baum, J.K. (2011). Potential impacts of emerging mahi-mahi fisheries on sea turtle and elasmobranch bycatch species. Biological Conservation, 144, 1841-1849. 
